\title{
RESOLVING TENSIONS BETWEEN DISABILITY RIGHTS LAW AND COVID-19 MASK POLICIES
}

\author{
Elizabeth Pendo, * Robert GATTER,** SEEMA MOHAPATRA***
}

\section{ABSTRACT}

As states reopen, an increasing number of state and local officials are requiring people to wear face masks while out of the home. Grocery stores, retail outlets, restaurants, and other businesses are also announcing their own mask policies, which may differ from public policies. Public health measures to stop the spread of the coronavirus such as wearing masks have the potential to greatly benefit millions of Americans with disabilities, who are particularly vulnerable to the impact of COVID-19. But certain disabilities may make it difficult or inadvisable to wear a mask.

Mask-wearing has become a political flashpoint, putting people with disabilities at risk. There are reports emerging that people with disabilities have been challenged, excluded from retail establishments, and even threatened with arrest for not wearing masks. Some anti-mask activists encourage their followers to falsely represent themselves as disabled to confound mask requirements, which has the potential to amplify skepticism and mistrust of people with non-obvious disabilities. Reports of violent conflict over mask-wearing add to these tensions. The first lawsuit challenging a mask requirement under federal disability rights law was filed in late May, and more are likely to follow.

Federal laws like the Americans with Disabilities Act ("ADA") prohibit discrimination on the basis of disability and require appropriate modification of public and private mask-wearing policies to accommodate the needs of individuals with disabilities. These laws, like other civil rights statutes, remain in force during

(C) 2020 Elizabeth Pendo, Robert Gatter, Seema Mohapatra.

* Professor of Law, Center for Health Law Studies, Saint Louis University School of Law; B.A., University of California Los Angeles; J.D., University of California Berkeley School of Law.

** Professor of Law, Center for Health Law Studies, Saint Louis University School of Law; B.A., Johns Hopkins University; J.D., University of Pennsylvania Law School; M.A. (Bioethics), Medical College of Wisconsin.

*** Associate Professor of Law and Dean's Fellow, Indiana University Robert H. McKinney School of Law; B.A. (Natural Sciences), Johns Hopkins University; J.D., Northwestern University School of Law; M.P.H. (Chronic Disease Epidemiology), Yale University School of Public Health. 
the pandemic and should operate as a check against any discrimination that might result from a mask requirement. However, misunderstanding of and noncompliance with these laws limits their effectiveness.

This Article provides the first expert analysis of the federal disability law framework that applies to mask policies issued by state and local officials, as well as by stores, restaurants, and other businesses that serve the public, and the often-confusing interaction between public and private policies. It argues that contrary to some popular assumptions, mask policies can be employed in a manner consistent with the $A D A$ and the Rehabilitation Act. Finally, it offers specific recommendations for the design and implementation of mask policies in a manner that accommodates both the rights of people with disabilities and the developing scientific knowledge of efforts to slow the spread of COVID-19.

\section{INTRODUCTION}

Public health measures to stop the spread of the coronavirus, such as mask-wearing, stay-at-home orders, and physical distancing, have the potential to greatly benefit people with disabilities, who are particularly vulnerable to the impact of COVID-19. But certain disabilities may make it difficult or inadvisable to wear a mask. In fact, the Centers for Disease Control and Prevention ("CDC") advise that face coverings should not be used by anyone who has trouble breathing, or is unconscious, incapacitated, or otherwise unable to remove the cover without assistance. ${ }^{1}$

Federal laws like the Americans with Disabilities Act ("ADA") ${ }^{2}$ prohibit discrimination on the basis of disability and require appropriate modification of public and private mask-wearing policies to accommodate the needs of individuals with disabilities. These laws, like other civil rights statutes, remain in force during the pandemic ${ }^{3}$ and should operate as a check against any discrimination that might result from a mask requirement. Contrary to the assertions of some anti-mask activists, mask policies can be

1. Considerations for Wearing Cloth Face Coverings, CTRS. FOR DISEASE CONTROL \& PREVENTION, https://www.cdc.gov/coronavirus/2019-ncov/prevent-getting-sick/cloth-face-coverguidance.html (last updated July 16, 2020) (last visited July 17, 2020).

2. Americans with Disabilities Act of 1990, 42 U.S.C. \$\$ 12101-12213, amended by Americans with Disabilities Amendments Act of 2008, Pub. L. No. 110-35, 122 Stat. 3553 (2008).

3. See Bulletin: Civil Rights, HIPAA, and the Coronavirus Disease 2019 (COVID-19), OFFICE FOR Civil Rights, U.S. DEP'T OF HEALTH \& HuMAN SERVS. (Mar. 28, 2020), https://www.hhs.gov/sites/default/files/ocr-bulletin-3-28-20.pdf; EEOC Continues to Serve the Public During COVID-19 Crisis, U.S. EQUAL EMP'T OPPORTUNITY COMM'N, https://www.eeoc.gov/newsroom/eeoc-continues-serve-public-during-covid-19-crisis (last visited May 28, 2020). 
implemented in a manner consistent with the ADA and the Rehabilitation Act. However, widespread lack of knowledge of and noncompliance with these laws raise serious concerns.

Consider a recent lawsuit challenging the mask requirement of a grocery chain in Pennsylvania. On May 26, 2020, Kimberly Pletcher filed a lawsuit claiming that a Pittsburgh-area grocery chain, Giant Eagle, discriminated against her on the basis of a respiratory condition that prevents her from safely wearing a mask, in violation of Title III of the ADA. ${ }^{4}$ The State of Pennsylvania's order requiring businesses to adopt mask requirements for customers provides an exception for individuals who cannot wear masks due to medical reasons (including children under two) and states that exempt individuals may enter the premises and "are not required to provide documentation of such medical condition." According to the complaint, Giant Eagle instituted a stricter policy that required all customers to wear masks, without exception, while on the premises of its Pennsylvania stores. Pletcher alleged that the owner of one Giant Eagle store posted publicly that the company decided against including a medical exception for safety reasons because "[i]t's too easy to make up an excuse not to wear a mask." ${ }^{\circ}$ She also reported inaccurate legal statements by Giant Eagle employees and security guards, including that an exception was not needed because customers who cannot wear masks can access goods through home delivery or curbside pickup. ${ }^{7}$ Additionally, Pletcher alleged that security guards verbally harassed and physically threatened customers with removal and arrest for trespass. ${ }^{8}$

We, as experts in disability law and public health law, provide analysis of the federal disability law framework that applies to mask policies issued by state and local officials, as well as by stores, restaurants, and other businesses that serve the public. We also offer recommendations for implementing mask policies in a manner that accommodates both the rights of people with disabilities and developing scientific knowledge of efforts to slow the spread of COVID-19.

4. Complaint, Pletcher v. Giant Eagle, Inc. (W.D. Pa. 2020) (No 2:20-cv-00754-NBF) [hereinafter Complaint].

5. Rachel Levine, Order of the Secretary of the Pennsylvania Department of Health Directing Public Health Safety Measures for Businesses Permitted to Maintain In-Person Operations, PA. DEP'T OF HEALTH (Apr. 15, 2020), https://www.governor.pa.gov/wpcontent/uploads/2020/04/20200415-SOH-worker-safety-order.pdf.

6. Complaint at 4 .

7. $I d$. at 5 .

8. $I d$. 


\section{MASK POLICIES AND PEOPLE WITH DisABILITIES}

One in four Americans - a diverse group of sixty-one million peopleexperience some form of disability. ${ }^{9}$ Certain disabilities, such as breathing issues, anxiety, autism, and sensory processing disorders, may make it difficult or inadvisable to wear a mask. ${ }^{10}$ Individuals with intellectual and developmental disabilities may not understand the need for masks or the specifics of evolving recommendations and requirements. ${ }^{11}$ Managing a mask also requires manual dexterity, which can be impacted by a wide range of muscular, skeletal, and neurological conditions. Standard opaque masks make it difficult to communicate with people with hearing impairments and who read lips.

Some disabilities that present a barrier to mask-wearing are immediately apparent, but others are not. There are reports emerging that people with disabilities have been challenged for not wearing masks, and even excluded from retail establishments, in addition to the situation described by Pletcher in her complaint. Bill Pratt, a father shopping in a Target outside of Chicago, was stopped by an employee when his young daughter, who has cerebral palsy, removed her mask in the store. ${ }^{12}$ When Pratt explained that he thought she was exempt due to her disability, the employee responded, "[D]o you have documentation to prove that? If not, I'm going to call the police." 13 Pratt then left without his purchases, explaining "[the employee] said he would call the police, and I had to get her out of there at that point."14

Mask requirements also put pressure on individuals with "hidden" or "invisible" disabilities, who in other circumstances might not disclose their disabilities because of concerns about stereotyping, stigmatization, and

9. Catherine A. Okoro et al., Prevalence of Disabilities and Health Care Access by Disability Status and Type Among Adults-United States, 2016, 67 Morbidity \& MORTAlity WKLY. ReP. 882,882 (2018).

10. See, e.g., Shannon Des Roches Rosa, Some Autistic People Can't Tolerate Face Masks. Here's How We're Managing with Our Son., WASH. Post (May 11, 2020), https://www.washingtonpost.com/lifestyle/2020/05/11/some-autistic-people-cant-tolerate-facemasks-heres-how-were-managing-with-our-son/; Donna Spencer, Don't Judge Those Not Wearing a Face Mask, Tam Says - They May Be Asthmatic, NAT'L POST (May 21, 2020), https://nationalpost.com/news/canada/masks-problematic-for-asthmatic-autistic-hearing-impairedpeople.

11. Rebecca Tan, Group Homes for Disabled Adults Grapple with the Spread of Coronavirus, WASH. POST (Apr. 18, 2020), https://www.washingtonpost.com/local/group-homes-for-disabledadults-grapple-with-the-spread-of-coronavirus/2020/04/18/ac2ecae2-7ff2-11ea-a3ee13e1ae0a3571_story.html.

12. Father Speaks Out After Store Worker Threatened to Call Police When His Daughter Removed Her Mask, NBC CHI. (May 5, 2020), https://www.nbcchicago.com/news/local/fatherhopes-to-educate-workers-about-exemptions-to-states-facial-coverings-order/2267171/.

13. Id.

14. Id. 
discrimination. For example, Paul Cohen, a man with severe asthma, was not permitted to enter a Boston grocery store because he was not wearing a mask. ${ }^{15}$ He reported, "I think everyone that can wear a mask should wear a mask. I'm just one of those people who can't ... . But it's embarrassing to have to stand there and explain myself to someone." 16 Some anti-mask activists encourage their followers to falsely represent themselves as disabled to confound mask requirements, which has the potential to amplify skepticism and mistrust of people with non-obvious disabilities. ${ }^{17}$ Adding to these tensions, there are reports of violent confrontations over maskwearing. ${ }^{18}$

Fears of scrutiny, exclusion, or arrest are especially troubling because people with disabilities are particularly vulnerable to the impact of the COVID-19 disease. They are more likely to fall into higher risk categories for serious cases of COVID-19 due to underlying conditions. According to the CDC, people with serious underlying medical conditions such as lung disease or asthma, heart conditions, diabetes, kidney disease, liver disease, and who are immunocompromised are at greater risk for severe illness from COVID-19. ${ }^{19}$ People in nursing homes and other congregate living situations, who are people with disabilities, elderly, or both, are also at increased risk. ${ }^{20}$ People with disabilities may also be less able to take protective measures against the spread of the virus. For example, it may not be possible to practice physical distancing if one relies on assistance from another person in one's activities of daily living, and many people who provide such assistance do not have access to personal protective equipment. $^{21}$

15. Felicia Gans, Cambridge Man Says He Was Turned Away from Grocery Store Without a Mask - Even Though He Is Exempt, BoS. Globe (May 14, 2020), https://www.bostonglobe.com/2020/05/14/nation/cambridge-man-says-he-was-turned-awaygrocery-store-without-mask-even-though-he-is-exempt/.

16. Id.

17. Bill Bostock, Anti-Mask Protesters are Trying to Commandeer US Disability Laws to Get into Stores Without Face Coverings, INSIDER (May 19, 2020), https://www.insider.com/anti-maskprotesters-cite-ada-disability-law-dodge-mask-requirement-2020-5; COVID-19 Alert: Fraudulent Facemask Flyers, ADA.GOV, https://www.ada.gov/covid-19_flyer_alert.html; Doron Dorfman, Fear of the Disability Con: Perceptions of Fraud and Special Rights Discourse, 53 LAW \& SOC'Y REV. 1051, 1052-53 (2019).

18. Neil MacFarquhar, Who's Enforcing Mask Rules? Often Retail Workers, and They're Getting Hurt, N.Y. TIMES (May 15, 2020), https://www.nytimes.com/2020/05/15/us/coronavirusmasks-violence.html.

19. Coronavirus Disease 2019 (COVID-19): People Who Are at Higher Risk for Severe Illness, CTRS. FOR DISEASE CONTROL \& PREVENTION, https://www.cdc.gov/coronavirus/2019-ncov/needextra-precautions/people-at-higher-risk.html (last updated June 25, 2020) (last visited July 17, 2020).

20. $I d$.

21. C.E. Drum, A. Oberg, K. Cooper, \& R. Carlin, COVID-19 \& Adults with Disabilities: Health and Health Care Access Online Survey Summary Report, AM. ASS'N ON HEALTH \& 
We do not have a clear national picture of the number of people with disabilities who have been infected or who have died as a result of COVID19 , but the data we do have reveals dramatic inequities. ${ }^{22}$ This is especially true for people who live or work in nursing homes and other long-term care facilities, who are reported to account for one-third of all COVID-19 deaths. ${ }^{23}$

People with disabilities also have well-founded concerns of discrimination and unequal treatment if they do seek health care services related to COVID-19, as decades of research show that people with disabilities experience significant disparities in health outcomes and access to health care services. ${ }^{24}$ Governmental and private responses to the COVID19 pandemic can compound these longstanding health inequalities. For example, in response to tremendous strain placed on our health care system by COVID-19, states, health care facilities, and professional organizations are developing triage protocols to determine how to allocate critical health care resources, especially ventilators, when there is not enough capacity to treat all patients. Disability advocates and organizations have raised serious concerns about the impact of triage policies that explicitly and implicitly exclude, disadvantage, or otherwise discriminate on the basis of disability. To date, three complaints about triage policies have been successfully

DISABILITY $8 \quad(2020), \quad$ https://www.aahd.us/wp-content/uploads/2020/05/COVID19_Summary_Report.pdf; Kristi L. Kirschner, Lisa I. Iezzoni, \& Tanya Shah, The Invisible COVID Workforce: Direct Care Workers for Those with Disabilities, THE COMMONWEALTH FUND (May 21, 2020), https://www.commonwealthfund.org/blog/2020/invisible-covid-workforce-direct-careworkers-those-disabilities.

22. For example, the City of St. Louis maps identify not only the number of COVID-19 cases in each of the City's zip codes, but also the percentage of residents in each zip code with a disability. See COVID-19 Cases by ZCTA, CITY OF ST. LOUIS, https://www.stlouismo.gov/government/departments/health/communicable-disease/covid-19/data/zip.cfm (COVID-19 cases); Social Vulnerability by Zip Code, CITY OF ST. LOUIS, https://www.stlouismo.gov/government/departments/health/communicable-disease/covid-19/data/social-

vulnerability.cfm (social vulnerability maps). Each of the two zip codes with the largest number of infections $(1,010$ or more per 100,000$)$ also have the highest percentage of residents with a disability (22.8 percent or more). See id.

23. Karen Yourish, K.K. Rebecca Lai, Danielle Ivory, \& Mitch Smith, One-Third of All U.S. Coronavirus Deaths Are Nursing Home Residents or Workers, N.Y. TIMES, https:/www.nytimes.com/interactive/2020/05/09/us/coronavirus-cases-nursing-homes-us.html (last updated May 11, 2020).

24. See, e.g., Elizabeth Pendo \& Lisa Iezzoni, The Role of Law and Policy in Achieving Healthy People's Disability and Health Goals Around Access to Health Care, Activities Promoting Health and Wellness, Independent Living and Participation, and Collecting Data in the United States, DEP'T OF HEALTH \& HuMAN SERVS.: OFFICE OF DiSEASE PREVENTION \& HEALTH PROMOTION 12 (2020), https://Www.healthypeople.gov/sites/default/files/LHP_Disability-HealthPolicy_2020.03.12_508_0.pdf. 
resolved by the U.S. Department of Health and Human Services Office of Civil Rights. ${ }^{25}$

\section{THE LAW - DISABILITY-BASED DISCRIMINATION DURING A PANDEMIC}

The ADA prohibits discrimination based on disability in employment (Title I), public programs, services and activities (Title II), public transportation and places of public accommodations (Title III), and telecommunications (Title IV). The ADA expands the protections of the Rehabilitation Act of $1973,{ }^{26}$ an earlier federal statute that prohibits discrimination based on disability in federal employment and in programs and activities that receive federal financial assistance. ${ }^{27}$ We focus here on the ADA and Rehabilitation Act, although additional protections may be available under other federal disability rights laws and state laws. ${ }^{28}$

These laws protect individuals with a physical or mental condition that substantially limits a major life activity, those with a history of disability, and those who are regarded as having a disability. ${ }^{29}$ Disability determinations are made on a case-by-case basis, although conditions that interfere with maskwearing identified above would be considered disabilities. Underlying health problems that make a person more vulnerable to COVID-19 such as lung disease, serious heart conditions, and diabetes, would be considered disabilities.

Together, the ADA and the Rehabilitation Act prohibit discrimination in mask policies by state and local officials, as well as by stores, restaurants, and other businesses that serve the public, and by employers. Orders from public entities requiring masks are subject to Title II of the ADA, as well as Section 504 of the Rehabilitation Act if the public entity is receiving federal financial assistance. Under these laws, qualified individuals with disabilities must have an equal opportunity to participate in or receive the benefits of services, programs, or activities of a public entity (often referred to as

25. See COVID-19 Medical Rationing \& Hospital Visitor Policies, CTR. FOR PUB. REPRESENTATION (June 9, 2020), https://www.centerforpublicrep.org/covid-19-medical-rationing/ (containing legal and ethical analyses, an updated list of complaints filed with the Department of Health and Human Services Office of Civil Rights, letters from advocacy organizations to federal and state officials, and media coverage).

26. 29 U.S.C. $\S 794 ; 45$ C.F.R. $\S 84.4,84.52$ (2019); 28 C.F.R. $\S 41.51$ (2019).

27. Section 1557 of the Affordable Care Act provides additional protections against disability discrimination in health care by amending the Rehabilitation Act to prohibit discrimination in certain health programs and activities. 42 U.S.C. $\$ 18116$.

28. See, e.g., A Guide to Disability Rights Laws, ADA.GOv, https://www.ada.gov/cguide.htm (last updated Feb. 24, 2020).

29. 42 U.S.C. $\S 12102$. 
"programmatic access"). ${ }^{30}$ In addition, public entities must administer services, programs, and activities in the most integrated setting appropriate to the needs of qualified individuals with disabilities. ${ }^{31}$

A state or local government may adopt legitimate safety requirements as long as the requirements are based on current, objective assessment of the actual risk, not on assumptions, stereotypes, or generalizations about people with disabilities. ${ }^{32}$ Although the science is not yet conclusive, there is good reason to conclude that public masking will help prevent the spread of SarsCoV-2, the virus causing COVID-19. ${ }^{33}$ The virus is most commonly spread by droplets expelled by infected people when they cough, sneeze, or even talk. ${ }^{34}$ Moreover, an infectious person can transmit SarsCoV-2 even when they do not have symptoms of illness. ${ }^{35}$ For these reasons, the CDC recommends that everyone wear a mask "in public settings where other social distancing measures are difficult to maintain (for example, grocery stores and pharmacies) especially in areas of significant community-based transmission." 36 Finally, while little data exists about the effectiveness of homemade masks, a recent systematic review finds that surgical "mask use provide[s] a significant protective effect." 37

Businesses open to the public must comply with similar requirements. Title III requires full and equal enjoyment of the goods, services, facilities, privileges, advantages, or accommodations of any place of public accommodation. ${ }^{38}$ As a public accommodation, a business may not impose eligibility criteria that either screen out or tend to screen out persons with disabilities, such as a requirement that all customers wear masks. ${ }^{39}$ However, it can impose legitimate safety requirements necessary for safe operation,

30. 28 C.F.R. $\$ 35.149$ (2019)

31. Olmstead v. L.C. ex rel. Zimring, 527 U.S. 581, 592 (1999).

32. Frequently Asked Questions About Titles II and III of the ADA, U.S. DEP'T OF JUSTICE, https://www.justice.gov/crt/frequently-asked-questions-about-titles-ii-and-iii-ada (last updated Aug. 6, 2015).

33. CDC Calls on Americans to Wear Masks to Prevent COVID-19 Spread, CTRS. FOR DISEASE CONTROL \& Prevention (July 14, 2020), https://www.cdc.gov/media/releases/2020/p0714americans-to-wear-masks.html.

34. How COVID-19 Spreads, CTRS. FOR DiSEASE CONTROL \& PREvention, https://www.cdc.gov/coronavirus/2019-ncov/prevent-getting-sick/how-covid-spreads.html (last updated June 16, 2020).

35. Ctrs. For Disease Control \& Prevention, supra note 1.

36. Id. (emphasis omitted).

37. Mingming Liang, Liang Gao, Ce Cheng, Qin Zhou, John Patrick Uy, Kurt Heiner, \& Chenyu Sun, Efficacy of Face Mask in Preventing Respiratory Virus Transmission: A Systematic Review and Meta-Analysis, TRAVEL MEDICINE AND INFECTIOUs DiseASE (2020), https://doi.org/10.1016/j.tmaid.2020.101751.

38. 42 U.S.C. $\S 12182$.

39. ADA Title III Technical Assistance Manual, ADA.GOv, https://www.ada.gov/taman3.html (last visited May 28, 2020). 
which must be based on actual risks and not speculation, stereotypes, or generalizations about people with disabilities. ${ }^{40}$ A state or local policy requiring or recommending masks while in public as described above would be strong support for similar mask requirements by retailers and other businesses. Even in the absence of a state of local policy, mask requirements in accord with current scientific evidence and CDC recommendations will likely pass muster.

Many public and private policies requiring masks include exceptions for disabilities that prevent mask wearing. The Pennsylvania policy referenced in the Pletcher case contained such an exception, for example. Even the City of Los Angeles's strict rule requiring a mask even while outside provides an exception for young children who are at risk of suffocation and people with certain disabilities who cannot wear a face covering. ${ }^{41}$ Similarly, Costco's policy requires all customers to wear masks except for children under two or individuals who are unable to wear a face covering due to a medical condition. ${ }^{42}$ These exceptions are in line with CDC advice that that face coverings should not be used by children under two or by anyone who has trouble breathing, or is unconscious, incapacitated, or otherwise unable to remove the cover without assistance. ${ }^{43}$

Even in the absence of an explicit exception, the ADA requires reasonable modifications to mask policies when necessary to provide programmatic access (under Title II) or access to goods and services (under Title III) for people who cannot comply for disability-related reasons. ${ }^{44}$ This means, for example, that a retailer that chooses to adopt a policy without explicit medical exceptions, such as the case with Giant Eagle, must still consider a modification or exception to the policy for individuals who are unable to wear masks for disability-related reasons. A modification or exception is not required if it would result in a "direct threat" (i.e. a significant risk of substantial harm that cannot be mitigated or eliminated), which is determined on a case-by-case basis using current objective evidence. $^{45}$

Under Title III, even if an exception to the mask policy is not feasible or would pose a direct threat, the business must provide alternate means of providing access to goods and services, such as home delivery or curbside

40. Id.

41. City of L.A. Guidance on Wearing Face Coverings in Public, CITY OF L.A., https://coronavirus.la/FaceCovering (last visited May 28, 2020).

42. Coronavirus, COSTCO WHOLESALE, https://www.costco.com/coronavirus.html (last visited May 28, 2020).

43. Considerations for Wearing Cloth Face Coverings, supra note 1.

44. U.S. DEP'T OF JUSTICE, supra note 32.

45. Id. 
pickup. ${ }^{46}$ Alternative means of providing access should be the option of last, rather than first, resort, and not a substitute for consideration of a modification.

One area of controversy is whether a person who is not wearing a mask can be asked about an underlying disability or may be required to provide documentation. Some jurisdictions explicitly address the issue, such as Pennsylvania's prohibition on requiring medical documentation from an individual who cannot wear a mask due to medical reasons. ${ }^{47}$ Title II and III do not directly address disability-related inquiries and confidentiality. ${ }^{48}$ Guidance from the Department of Justice on Title II provides that a public entity should not make "unnecessary inquiries" concerning disability, ${ }^{49}$ which suggests some latitude to ask questions necessary to determine if a disability-based exception applies. Similarly, although the employment title of the ADA (Title I) does not require any applicant or employee to reveal disability-related information, it does permit an employer to ask appropriate questions as part of an interactive process once an employee requests reasonable accommodation. ${ }^{50}$ Title II regulations also permit limited and narrowly-focused questions to determine whether an animal is a service animal, when it is not obvious. ${ }^{51}$

\section{THE WAY FORWARD}

It is not an obvious decision whether to require or merely to recommend mask use by apparently healthy people when they are out of their homes and indoors with others. On the one hand, masks are likely effective at preventing the spread of the virus, which weighs in favor of requiring them. On the other hand, we have already seen examples of unreasonable and even illegal enforcement of mask requirements against those who are uniquely burdened by this pandemic, including — as noted above-people with disabilities, and this weighs against requirements and in favor of recommendations. We conclude that, on balance, mask recommendations are the better answer for now.

46. $I d$.

47. Levine, supra note 5.

48. See Equip for Equality, Confidentiality Requirements Under the ADA, GREAT LAKES ADA CTR. 9 (Apr. 2018),

http://www.adagreatlakes.org/Publications/Legal_Briefs/BriefNo31_Confidentiality_Requirement s_Under_the_ADA_2018.pdf.

49. ADA Title II Technical Assistance Manual, ADA.GOv, https://www.ada.gov/taman3.html (last visited May 28, 2020).

50. 42 U.S.C. $\$ 12112(d)(4) ; 29$ C.F.R. § 1630.14(c) (2019).

51. See 28 C.F.R. $\S 35.136(f)$ (2011). 
Too many state officials, local officials, and store representatives remain ignorant of limits the law places on questions they may ask people who say they cannot wear a mask due to a disability. Consequently, those with nonobvious disabilities will be burdened with potentially inappropriate questions and, as we have seen, even threats if they choose to go out in public without a mask. This situation is made more likely given that some political activists, who associate mask-wearing with governmental oppression or disloyalty to President Trump, have encouraged their followers to misrepresent themselves as disabled so as to confound mask requirements. Mask recommendations, unlike requirements, should eliminate the need for an enforcement mechanism and thereby substantially reduce the risk that a person with a non-obvious disability is faced with inappropriate or intrusive questioning.

Mask recommendations must be coupled with education on the substance of overlapping government orders and institutional policies as well as the requirements of the ADA. Recall, for example, that employees and security personnel at one store in the grocery chain sued in the Pletcher case erroneously claimed that Pennsylvania's order permitted the store to refuse entry to a person unable to wear a mask because of a disability so long as the store provided access through home delivery or curbside pickup. As this pandemic plays itself out, orders and policies are likely to change many times as science learns more about the virus and as jurisdictions proceed (and/or back-track) through the phased re-opening of businesses. These periodic changes will increase the opportunity for officials and store employees to misunderstand the rules and any exceptions when enforcing mask requirements against people with disabilities. Again, mask recommendations, even ones that change routinely, will not put officials or store employees in a position to misinterpret standards as will requirements.

Mask recommendations will harness at least some of the public health benefit of a requirement while giving public health officials and store owners an opportunity to better prepare for widespread mask-wearing. Public health officials and regulators need to assure that police as well as retail outlets are better educated about public orders and the applicable requirements of the ADA (for example, what questions may be asked and when alternative means of providing access are appropriate). Furthermore, some of the tensions between customers with disabilities and retail employees and security personnel could be lessened by clearly communicating policies to customers in advance, including exceptions and alternative means of accessing goods and services. Employees and security personnel should also be educated on the specifics of mask-wearing policies that apply to customers, and the applicable requirements of the ADA. Under the circumstances, then, it would appear reasonable for a retail employee to ask a customer if there is a 
disability-related reason for not wearing a mask as otherwise required and, if not wearing a mask is a legitimate safety issue under the circumstances, to offer alternative methods of providing services if necessary. Similarly, educating the public about disability-related exceptions to state and local policies, including questions that police or other representatives may ask, would be helpful.

Agencies, organizations, researchers, and others have documented that the ADA and Rehabilitation Act are underenforced, ${ }^{52}$ which suggests that these laws will not be an effective check on discriminatory enforcement of mask requirements against people with disabilities. Moreover, even when disability discrimination claims are brought, they may not be well received in federal courts. Two of us have noted elsewhere that victims of racial discrimination during this pandemic are likely to find that courts are less accessible, that judges are deferential to those attempting to serve the public's health, and that courts are adopting lenient standards of review on the rationale that, during a pandemic, "civil liberties take a back seat to civil order." 53 The same may be true for victims of disability discrimination.

We recognize that mask recommendations are unlikely to result in the same degree of mask-wearing as would mask requirements and, therefore, that mask recommendations are not as likely to slow the spread of the virus as would mask requirements. Nonetheless, the risk of uninformed and discriminatory enforcement of mask requirements against people with disabilities undercuts the justification for mask requirements, at least until we are better prepared.

52. Pendo \& Iezzoni, supra note 24 at 58.

53. Robert Gatter \& Seema Mohapatra, COVID-19 and the Conundrum of Mask Requirements, 77 WASH. \& LEE L. REV. ONLINE 17, 27 (2020). 